\title{
Eficacia política, ética y corrupción en el Gobierno de Guayaquil (1779-1790)*
}

\author{
por \\ Miguel Molina Martínez \\ Catedrático de Historia de América \\ Departamento de Historia Moderna y de América \\ Universidad de Granada
}

El gobierno de Ramón García de León y Pizarro en Guayaquil mereció los elogios de la Corona y más tarde de la investigación histórica. Sin embargo, algunos de sus actos podrían ser cuestionados por su dudosa ética y moralidad. Las amenazas, sobornos, medidas de presión, favoritismos, etc. formaron parte de su práctica política en beneficio propio y el de su clan. Este artículo analiza algunos de esos comportamientos irregulares en el contexto del debate sobre la corrupción de la burocracia colonial.

PALABRAS Clave: Guayaquil; siglo XVIII; corrupción; administración colonial.

Existe hoy bastante consenso en aceptar la idea de que el fenómeno de la corrupción en la administración colonial española, lejos de ser un hecho marginal, era en sí mismo parte constituyente del sistema. Fue Horst Pietschman quien, a partir de los años de 1980, abordó de forma sistemática esta cuestión abriendo una fructífera línea de investigación todavía no agotada en la actualidad $^{1}$. A sus planteamientos siguieron, entre otros, los trabajos de Kenneth Andrien $^{2}$, Eduardo Saguier ${ }^{3}$, Alejandro Cañeque ${ }^{4}$, Alfredo Moreno y Nuria Sa-

* Este artículo forma parte del Proyecto I+D HAR2009-10094 (subprograma HIST) del Ministerio de Ciencia e Innovación, con el título «Compra de cargos públicos, ejercicio del poder y redes sociales en el espacio de la Audiencia de Quito (1655-1797)».

1 Pietschman, Horst, 1982: 11-37; 1989 (Particularmente el capítulo «Sobre el Estado patrimonial»: 163-181); 2003: 47-84.

2 Kenneth, 1984: 1-20; 1986: 493-521.

3 Saguier, 1989: 269-303.

4 Cañeque, 2001: 5-57. 
la $a^{5}$, Tamar Herzog ${ }^{6}$ o Scarlett O'Phelan ${ }^{7}$ quienes desde diferentes perspectivas, épocas y regiones han contribuido a una mejor comprensión de dicho fenómeno. Dejando al margen los aspectos metodológicos y conceptuales inherentes al tema ${ }^{8}$, pueden aceptarse una serie de pautas y elementos definitorios de la práctica corrupta de los administradores. La propuesta de Pietschman incluía el contrabando, el cohecho, los sobornos, el favoritismo cortesano, el clientelismo y la venta de oficios entre los mecanismos de la corrupción a la que identificaba como una «trasgresión de los preceptos legales y normativos con fines propios o de grupo $»^{9}$. Por su parte, Torres Arancivia concluyó que para la existencia de una situación de corrupción debían de darse tres condiciones: que la justicia del rey fuera desvirtuada, que la ley fuera violentada y que surgiera la protesta del sector social perjudicado o amenazado ${ }^{10}$.

En sintonía con tales planteamientos, este artículo pretende exponer algunos comportamientos del gobernador de Guayaquil, Ramón García de León y Pizarro, que pueden arrojar nueva información sobre este tema. Abel Romeo Castillo, gran estudioso de la historia de la gobernación de Guayaquil en la segunda mitad del siglo XVIII, trazó una sucinta panorámica de la labor desempeñada por Ramón García de León y Pizarro en el tiempo de su mandato entre 1779 y 1790 . Destacó sus esfuerzos en la promoción de la ciudad visible a través de un importante programa de obras públicas y puso de manifiesto los positivos resultados de su gestión económica ${ }^{11}$. Abundando en esta opinión, Filemón Arribas lo definió como un «magnífico ejemplo de la actividad colonizadora de un militar español con dotes de buen gobernante» ${ }^{12}$. La evidencia de que su actuación satisfizo las expectativas de la Corona la ofrece su ascendente carrera que le llevó desde el gobierno de Guayaquil, al de Salta y, finalmente, a la presidencia de la Audiencia de La Plata. A la extensa relación de condecoraciones sumó en 1812 la del Título de Castilla $^{13}$.

5 Moreno Cebrián y Sala i Vila, 2004.

6 Herzog, 2004.

7 O'Phelan, 2005: 13-33.

8 Torres Arancivia, 2007. Pietschmann, 1998: 31-52.

9 Pietschmann, 1989: 163-181.

10 Torres Arancivia, 2006.

11 Castillo, 1978: 220-224.

12 Arribas, 1970: 45.

13 Dicha concesión se incluye en la Orden de 11 de agosto de 1812. Carta de Fernando de Abascal al ministro de Gracia y Justicia, Lima, 31 de marzo de 1813, Archivo General de Indias (AGI), Lima, legajo 744. En ella el virrey informa haber comunicado al propio interesado la obtención de aquel Título. 
Pese a lo que pudiera desprenderse de tan magnífica hoja de servicios, su paso por la gobernación de Guayaquil no fue en modo alguno tranquilo. Durante la década que estuvo al frente de la misma se sucedieron frecuentes enfrentamientos con otras instituciones y con personalidades relevantes de la ciudad, que trascendieron hasta la misma Corte. El resultado fue la puesta en marcha de un proceso dirigido a esclarecer los diferentes cargos de los que se le acusaba y determinar su veracidad o falsedad. El desarrollo del mismo dio origen, a su vez, a nuevos conflictos que pusieron de relieve la rivalidad existente entre los diferentes bandos radicados en Guayaquil y, por extensión, en Quito $^{14}$. Debe tenerse en cuenta que el gobernador de Guayaquil era hermano del presidente-regente de la Audiencia, José García de León y Pizarro, a quien en gran medida debía su cargo. El proceso demostró que las críticas alcanzaban a toda la familia y que formaban parte de un movimiento de reacción ante los modos y comportamientos políticos de los García de León y Pizarro, tachados de corruptos o de dudosa moralidad.

Fue en 1787 cuando la Corona tuvo conocimiento del malestar existente en Guayaquil a través de los escritos representados por tres vecinos de la ciudad ${ }^{15}$. En ellos se contenían graves acusaciones contra el gobernador. Sus autores coincidían en responsabilizar de la lamentable situación que vivía Guayaquil a la pésima política del gobernador y de su teniente Mexía, confabulados con otros individuos en la defensa de intereses personales. Abuso de poder, extorsión, fraude o manipulación de la justicia eran, entre otras, las acusaciones que abiertamente se exponían en estas representaciones, lo que equivalía a considerar su gestión directamente como corrupta ${ }^{16}$. Tal información debió sorprender al rey ya que hasta entonces sólo tenía constancia del excelente trabajo desarrollado por el gobernador, traducido en ascensos y condecoraciones.

El propio Ramón García de León y Pizarro se había encargado de hacer llegar al monarca sus méritos a través de un Memorial donde enumeraba sus desvelos para aliviar los problemas defensivos de Guayaquil, mejorar las arcas rea-

14 El problema salpicó a la Real Audiencia, cuyos ministros adoptaron posiciones encontradas. Véase Molina Martínez, 2008: 153-173.

15 Representación de Joaquín Pareja al Rey, Guayaquil, 4 de diciembre de 1787, AGI, Quito, legajo 271; Representación de Antonio Marcos al Rey, Guayaquil, 19 de diciembre de 1787, AGI, Quito, legajo 271; Representación anónima sobre los negocios del gobernador de Guayaquil, Guayaquil, 4 de diciembre de 1787, AGI, Quito, legajo 380.

16 La representación de Joaquín Pareja era la más extensa y dura. El extracto que de ella hizo el Consejo tiene 31 folios. En ella también se recogen críticas a José García de León y Pizarro por lo realizado durante su visita a Guayaquil.

17 Memorial de Ramón García de León y Pizarro a Su Majestad, Guayaquil, 30 de abril de 1780, Archivo General de Simancas (AGS), SGU, legajo 6828. 
les y agilizar la administración de justicia ${ }^{17}$. Particular énfasis puso en resaltar las cuestiones defensivas, hecho lógico dado el estado de guerra con Inglaterra en aquellos días y la precariedad de medios disponibles para afrontar un eventual ataque. Con orgullo presumía de las medidas adoptadas en estos términos:

«He trabajado incesantemente en la disposición de las Milicias, que no tenían instrucción alguna... He reparado todos los pertrechos de guerra, que se hallaban abandonados e inútiles y tengo ya montada y de servicio bastante artillería... He construido y acabado un baluarte y dos baterías con que está guardada la ciudad por la parte del río... "Y aunque su costo - señalaba refiriéndose al baluarte de San Carlos- pase de siete mil pesos, no se ha impedido un solo maravedí de la Real Hacienda: Por mis estímulos, lo han ejecutado todo algunos vecinos de honor a sus expensas bajo de mi dirección... En la misma forma, y sin gasto alguno de la Real Hacienda, se han construido dos baterías"》» 18 .

El Memorial contaba con el refrendo del tesorero y el contador de las Cajas Reales que se hacían eco, además, de otros méritos y servicios ${ }^{19}$. No quedó a la zaga el presidente de Quito en ponderar el esfuerzo de su hermano. En reiteradas cartas dejó constancia de su benéfica gestión en la defensa de Guayaquil y en otras actuaciones dentro de la ciudad ${ }^{20}$. En consecuencia Carlos III declaró estar «muy satisfecho de su celo y actividad», concediéndole en 1783 por estos servicios el grado de corone ${ }^{21}$.

Sin embargo, la expresada autocomplacencia del gobernador no era compartida por todo el vecindario, como tampoco suscitaban simpatía las estrategias de que se valió para su gestión. En concreto, Joaquín Pareja denunció en su representación que Pizarro había utilizado las obras de fortificación de la ciudad para su enriquecimiento personal. Señaló que ocupó en ellas a la tropa y a los indios y obligó a los pueblos cercanos a que proporcionasen con su propio dinero los materiales necesarios, imponiendo multas cuyo montante se apropiaba. Además, lamentó el crecido gasto ocasionado por la estancia de las tropas que su propio hermano le había enviado y que no llegaron intervenir porque finalmente la armada inglesa nunca atacó. La denuncia de Pareja ponía al descubierto que la conducta del gobernador no había sido tan ejemplar como reflejaban otros testimonios. Si Pizarro presumía de buen gobierno por el ahorro conseguido para las arcas reales en las obras de fortificación, Pareja

18 Idem.

19 Certificación de Luis Ariza y Gabriel Fernández Urbina, Guayaquil, 30 de abril de 1780, AGS, SGU, legajo 6828.

20 Cartas de José García de León y Pizarro a José de Gálvez, Quito, 18 de marzo de 1780; 18 de mayo de 1780; 17 de febrero de 1781, AGS, SGU, legajo, 7051.

21 Título de coronel graduado de infantería a Ramón García de León y Pizarro, San Ildefonso, 17 de septiembre de 1783, AGS, SGU, legajo 6828. 
denunciaba que las contribuciones del vecindario no fueron tan inocentes y altruistas, como se quería hacer ver, sino que se realizaron bajo presión y amenazas.

Joaquín Pareja presentó testimonios que avalaban sus afirmaciones. Algunos de ellos, firmados por el mismo gobernador, demostraban que hubo amenazas a la población para que contribuyese gratuitamente con maderas a las obras de fortificación. Así se desprende de una carta dirigida por Pizarro a Antonio de los Ríos, vecino de Guayaquil y dueño de la hacienda La Candelaria, en la que le hacía comprender la necesidad de proporcionar madera de todo tipo para la defensa del puerto y le consideraba «obligado a este importante servicio de Su Majestad». Finalmente le instaba a él y a otros vecinos a que ayudasen a esta empresa de forma que

«a ninguno le será admitida la más leve excusa, ni pretexto para contribuir a esta labor con sus personas y herramientas, so la pena de que el comisionado los remita bien asegurados a esta Real Cárcel donde se le dé el castigo correspondiente; y por el contrario, portándose fieles servidores del Soberano, se les dará en su Real Nombre las gracias por el servicio que en este tan importante asunto le rindan $»^{22}$.

También esclarecedor era el testimonio de Juan Antonio Caamaño quien, habiendo sido condenado a proporcionar hasta 300 estacas de madera, se mostraba totalmente dispuesto a facilitarlas, incluso en mayor cantidad, con tal de eludir la prisión ${ }^{23}$. En otra carta Pizarro pedía a los vecinos del pueblo de Baba, a través de su teniente de gobernación, que contribuyeran con diferentes cantidades de maderas para la misma finalidad de forma «desinteresada, como lo han hecho en las demás poblaciones» y que entendieran aquello como un servicio al rey por el que se les daría «las más debidas gracias» ${ }^{24}$.

Si este comportamiento levantó suspicacias y recelos entre los vecinos ya desde los primeros meses de gobierno, los roces con el ayuntamiento, que fueron constantes desde su toma de posesión, tampoco contribuyeron a la tranquilidad de la ciudad. Su afán por imponer su criterio en todas las deliberaciones y forzar las elecciones a su conveniencia molestó sobremanera al Cabildo, celoso de sus fueros y jurisdicción ${ }^{25}$. Polémicas provocadas a causa de si los ca-

22 Carta de Ramón García de León y Pizarro a Antonio de los Ríos, Guayaquil, 27 de noviembre de 1779. AGI, Quito, legajo 380.

23 Carta de Juan Antonio Caamaño a Ramón García de León y Pizarro, Guayaquil, 31 de diciembre de 1779, AGI. Quito, legajo 380.

24 Carta de Ramón García de León y Pizarro al teniente de gobernado de Baba, Guayaquil, 4 de enero de 1780. AGI, Quito, legajo 380.

25 En realidad las tensiones se remontaban al anterior gobernador, el coronel Francisco Ugarte, que había encarcelado a dos regidores y en nada había contribuido al buen entendimiento institucional. Véase Castillo, 1978: 185 y ss. 
pitulares debían acompañar o no al gobernador a su casa los días de cabildo, enfrentamientos sobre el señalamiento de sitio para sentarse en las sesiones, en las procesiones o funciones públicas, así como otras disputas por rivalidades entre grupos enrarecieron ostensiblemente el ambiente de Guayaquil ${ }^{26}$. Uno de los conflictos, que alcanzó gran resonancia e incluso fue debatido en Quito por los oidores de la Real Audiencia, fue el originado por la actuación de los músicos de la ciudad con motivo de la festividad de Santiago Apóstol en 1781.

En esta ocasión el problema surgió cuando el teniente asesor de Pizarro, José Mexía, arrestó a los músicos que tocaban en la casa capitular. Les acusó de desaire al gobernador por no haber acudido antes a su casa a tocar. Era costumbre que la víspera de Santiago se celebrara una función de homenaje al Estandarte Real que se custodiaba en el Ayuntamiento y que con tal motivo actuaran en ella los músicos. Sorprendentemente, Mexía, ejerciendo la máxima autoridad porque el gobernador se hallaba fuera de la ciudad recuperándose de una dolencia, ordenó la prisión de los músicos. De nada sirvieron los llamamientos de Marcos de Abellán — regidor decano - para que desistiera de su actitud al considerarla un grave menosprecio al rey, representado en el Estandarte. A las nueve de la noche un piquete de soldados entró en la casa capitular e hizo prisioneros a los músicos. Abellán ordenó que Baltasar de Avilés y Alejo Guiraldes Pereira, depositario general y escribano respectivamente, que presenciaron la escena, levantasen acta de lo acontecido para elevar la queja a los tribunales superiores. La certificación de éstos es bastante prolija y se extiende en todo lujo de detalles sobre el altercado ${ }^{27}$. Por ella sabemos de las negociaciones realizadas para evitar la prisión y de su fracaso para mayor escándalo de la población.

Toda la responsabilidad de lo sucedido recayó sobre José Mexía, que desoyó las voces que le aconsejaban no interrumpir los honores que se dispensaban al monarca a través de su Estandarte. El capitán Jacinto Bejarano, a cuyo mando estaban los soldados que intervinieron, no dudó en culpar del suceso al teniente de gobernador con quien no mantenía buenas relaciones. Para justificar su intervención arremetió contra éste afirmando que «trató con el mayor desprecio al Real Estandarte» y que era notorio su «ardimiento y fogosidad». Pedía a las autoridades que tomaran medidas «de modo que no abuse de la real jurisdicción y que causas tan inocentes no se inviertan por este ministro ni se caractericen de alborotos», y concluía que «a mí no se me siga el deshonor de

26 Los conflictos entre las autoridades y los mismos miembros del cabildo venían siendo una constante en la región. Véase Ramos Gómez, 1992: 179-196; 1993: 249-272; 2005: 53-77. Ruigómez Gómez, 2004-2007: 77-92.

27 Certificación de Baltasar de Avilés y Alejo Guiraldes Pereira y Castro, Guayaquil, 25 de julio de 1781, AGI, Quito, legajo 380. 
haber prestado auxilio» ${ }^{28}$. Los ministros de la Audiencia decidieron abrir una investigación requiriendo a los alcaldes ordinarios de Guayaquil para que presentaran informes que esclarecieran lo ocurrido y así lo cumplieron haciendo comparecer a músicos y soldados para que dieran testimonio de los hechos. Las declaraciones tuvieron lugar a lo largo del día 23 de agosto y nada nuevo arrojaron sobre lo ya conocido ${ }^{29}$. Los músicos corroboraron los informes anteriores $^{30}$. Los soldados reconocieron los hechos pero declararon que actuaron a las órdenes de Jacinto Bejarano, autoridad militar en ausencia del gobernador, y que exhibía una orden de José Mexía. Concluyeron que apresaron a los músicos porque cumplían órdenes.

Hasta finales de 1781 no hubo pronunciamiento de la Real Audiencia y cuando se produjo fue para censurar el comportamiento de Mexía. Amparándose en las leyes existentes, que recomendaban la mayor autoridad y honra para el pendón real, el fiscal sostenía que

«debió el teniente general de Guayaquil dejar en su antiguo estilo la celebridad que aquella ciudad hace colocando el pendón real en las casas del cabildo sin precisar a los músicos a que desertasen, mayormente estando excusado de llevarlos a las casas del gobernador porque se hallaba ausente. Menos pudo arrestarlos como lo hizo con notable escándalo y desairando al alférez real, al mismo cabildo, y al Real Estandarte $»^{31}$.

\section{Y concluía:}

«Queda advertido el teniente de guerra del desagrado con que en este tribunal se ha visto su procedimiento ajeno de la reflexión y prudencia que demandaba el caso

28 Carta de Jacinto Bejarano a la Audiencia de Quito, Guayaquil, 30 de julio de 1781. AGI, Quito, legajo 380.

29 Representación de Manuel Ximénez Palacios y Tomás Francisco Calvo, alcaldes ordinarios, a la Real Audiencia. Guayaquil, 25 de agosto de 1781. AGI, Quito, legajo 380.

30 Como ejemplo, véase el testimonio del violinista Damián Morales. Dijo éste que acudió a las seis y media de la tarde junto al resto de los músicos a tocar a la Casa consistorial, como era la costumbre y rendir honor al Estandarte Real. Tocaron hasta las nueve de la noche en presencia del regidor decano, Marcos Abellán, y el depositario general, Baltasar de Avilés. A esa hora se presentó un soldado de orden del teniente general diciéndoles que estaban presos. El regidor decano medió en el asunto pero sin éxito. El depositario general se ofreció para dialogar personalmente con el teniente general Mexía, lo que hizo también sin éxito. Finalmente acudió un grupo de soldados milicianos de la sierra siguiendo las órdenes de Mexía y los músicos fueron encarcelados. Al día siguiente fueron puestos en libertad para que tocaran en la fiesta en honor de Santiago y concluida ésta fueron de nuevo arrestados y en prisión estuvieron hasta las cinco de aquella tarde. Luego fueron llamados ante la presencia de Mexía quien les reprendió por no haber ido a la casa del gobernador a tocar antes que al Cabildo.

31 Informe del fiscal de la Real Audiencia, Quito, 11 de diciembre de 1781, AGI, Quito, legajo 380 . 
y juntamente se le aperciba que en lo sucesivo guarde buena armonía con los regidores para conservar la paz pública que debe ser uno de los principales objetos de los magistrados y evitar nuevos recursos... debiendo dichos regidores observar lo mismo con el teniente general» ${ }^{32}$.

Aunque formalmente aparentase acatar la resolución de la Audiencia, el gobernador Pizarro tomó partido por Mexía y defendió su comportamiento. Por ello, trató de zanjar el asunto de la forma más rápida y velada posible; intencionadamente eludió comunicar al Cabildo la resolución de la Audiencia, por más que fuera invitado en varias sesiones a que la hiciera pública para desagravio de la propia institución. Sin embargo, tantas excusas y evasivas por parte de Pizarro tuvieron el efecto contrario al deseado. Lejos de olvidarse, el contencioso de los músicos seguía aún sin resolverse en 1789 , fecha en la que volvió a plantearse a propósito de un nuevo conflicto que enfrentó a los mismos protagonistas. En ese año, al debatirse en sesión capitular la fijación de la fecha y actos con que la ciudad debía festejar la proclamación de Carlos IV, Joaquín Pareja recordó al gobernador que aún no había hecho pública al Cabildo la provisión de la Audiencia de 1782 y vinculó su notificación a la celebración de dichos actos. Argumentaba que la institución seguía estando agraviada mientras no se le presentara oficialmente el documento que reprobaba a Mexía por el ultraje al Estandarte Real y consideraba, por tanto, coherente retrasar su participación en aquella solemnidad hasta que se resolviera el contencioso.

El incidente puso de manifiesto que las relaciones entre el gobierno y los regidores eran bastante tensas. El gobierno, tratando de ejercer su autoridad a costa de controlar las iniciativas de los capitulares; éstos, defendiendo su autonomía y las viejas libertades que caracterizaron al órgano municipal. Un terreno abonado para que las rivalidades y odios personales afloraran con inusitada dureza y así ocurrió entre el teniente de gobernador Mexía y el regidor Pareja. El primero se apresuró a denunciar a Pareja por su actitud irresponsable y por oponerse a una «diligencia tan necesaria como obligatoria», señalando que el único móvil que le impulsaba era el ataque personal: «Sólo por contentar - decía - su genio turbulento y lograr la criminal satisfacción de inquietarme y ultrajar mi respeto y autoridad» ${ }^{33}$. Desde su punto de vista, el contencioso del Estandarte Real no era excusa suficiente para «diferir por un solo día el reconocimiento auténtico y público de la soberanía del nuevo Rey, que debe

32 La Audiencia hizo suyo este dictamen y así lo remitió a Ramón Pizarro para que se lo notificase a su teniente de gobernador. Real Provisión de la Audiencia de Quito, Quito, 15 de enero de 1782. AGI, Quito, legajo 380.

33 Representación de José Mexía a la Real Audiencia, Guayaquil, 4 de agosto de 1789. AGI, Quito, legajo 380. 
hacerse inmediatamente en esta ciudad». Estaba convencido de que Pareja actuaba impulsado más por motivos inconfesables que por la exaltación del monarca y la fidelidad de los vasallos. Le calificaba de «hombre inquieto, insubordinado y turbulento», que había removido un viejo asunto ya olvidado con el único fin de desprestigiarle y saciar su venganza. Su conducta manifestaba «el veneno de su corazón, el rencor inextinguible de que hace una ostentación vergonzosa y el respeto e insubordinación a sus superiores de que con no menos delito se gloria». Llamaba la atención sobre el hecho de que Pareja en todos sus escritos le negaba el título de «señor», que por otra parte prodigaba entre sus compañeros regidores, para demostrar que todo cuanto hacía llevaba «la impresión del orgullo y la falta de respeto a las superioridades».

Sobre la cuestión del Estandarte Real y los músicos, Mexía afirmaba que ya estaba zanjada toda vez que la Real Audiencia emitió su veredicto y que él recibió «con sumisión y la mayor resignación», a pesar de que hubiera podido apelar pues, en su opinión, los informes elaborados en su momento por los alcaldes ordinarios carecían de «la imparcialidad que exige la justicia» y habían sido dirigidos «por el consejo de mis enemigos». Por todo ello, solicitaba que el Cabildo no postergara la solemnidad de la entronización del monarca y que Pareja fuera castigado por «sus excesos y comportamiento incorregible».

La réplica de éste no se hizo esperar, haciendo ver a la Audiencia, en términos bastante duros, las falsedades vertidas por Mexía en su escrito, redactado sólo con el «depravado intento de quedar impune en el escandaloso crimen que ha incurrido ultrajando el Real Estandarte» ${ }^{34}$. Se atrevió a descalificarlo con los más siniestros trazos:

«Es un tirano de la paz - escribió- y versa mal su oficio fomentando discordias porque de ellas le resulta su bienestar; que tiene sed de la sangre humana; que es un hombre libertino, que desnudo enteramente de los sentimientos de religión sirve escandalosamente y como si no hubiese rey; que su soberbia y erguidez le han hecho creerse deidad, siendo en realidad ídolo por cuya boca solo salen malignos influjos y crueles vaticinios; que es un monstruo que cuanto respira es veneno, cuanto vierte ira y cuanto exercita son artificios, inventivas y fraudes con que destruye a todos aquellos que no le rinden adoraciones... hombre sangriento y criminal que se juzga tan independiente que hace delincuente ostentación de que cuando toma la pluma corre por sus dedos fuego y azufre y que últimamente este hombre es el origen y causa primaria de cuantos males se han experimentado en esta ciudad que cada día se aumentan sin término» ${ }^{35}$.

34 Representación de Joaquín Pareja a la Real Audiencia, Guayaquil, 27 de septiembre de 1789. AGI, Quito, legajo 380.

35 Idem. 
La Real Audiencia, a la vista del informe fiscal, consideró que era prioritario rendir homenaje al rey y ordenó al ayuntamiento que procediera a ello «con la solemnidad acostumbrada sin diferirla con ningún pretexto». No obstante, para satisfacer la petición municipal y descartar cualquier excusa, ordenó también que el gobernador Pizarro exhibiera en una próxima sesión de los capitulares la providencia objeto de la polémica ${ }^{36}$. Conocida esta resolución, el Cabildo la acató y procedió a fijar el día para la conmemoración, recordando al gobernador que también cumpliese su parte. Sorprendentemente éste se excusó de hacerlo diciendo que lo haría en una próxima sesión y lo mismo repitió en las sucesivas reuniones. Esta negativa a dar cuenta del documento alentó la idea de que había sido destruido y, en todo caso, que Pizarro y Mexía pretendían que se llevara a cabo la proclamación real sin que el Cabildo fuese desagraviado, en el convencimiento de que una vez finalizada la celebración sería olvidada la polémica. No estaban los regidores, y menos Pareja, dispuestos a quedar nuevamente desairados y, por consiguiente, «llena de ensanches la soberbia del teniente gobernador y burladas las superiores determinaciones de Vuestra Alteza ${ }^{37}$. Firmes en esta determinación, solicitaron a la Real Audiencia que expidiera una copia de la provisión de 1782 para remitirla directamente al Cabildo y que previniera al gobernador de abstenerse de negar la convocatoria de una sesión en que aquélla se hiciera pública ${ }^{38}$. Como quiera que Pareja elevara su recurso hasta el virrey, también éste hubo de pronunciarse y lo hizo confirmando las pretensiones del ayuntamiento. Por un lado, declaró que por ningún motivo se retrasara más la función de proclamación del rey «antes bien se resuelva y execute con la mayor brevedad y con todo el decoro, pompa y majestad que corresponde»; por otro lado, que en el primer cabildo que se celebrara se dejara constancia de la provisión. Todavía satisfizo más los ánimos de los capitulares la conclusión final de que los comportamientos de Mexía fueron los que ocasionaron aquel suceso «por haber obrado con menos circunspección de la que debiera» ${ }^{39}$. Finalmente la proclamación de Carlos IV se celebró en Guayaquil el 13 de diciembre de 1789, casi tres meses después que en Quito, quedando expuesto el Estandarte Real en una tribuna frente a la puerta del ayuntamiento.

Los enfrentamientos entre Pizarro y el Cabildo de Guayaquil no cesaron por una causa $\mathrm{u}$ otra. Las presiones ejercidas por el gobernador con motivo de

36 Real Provisión de la Audiencia de Quito, Quito, 4 de septiembre de 1789. AGI, Quito, legajo 380.

37 Idem.

38 La Audiencia aceptó en estos mismos términos lo solicitado, según consta en la Real Provisión de 9 de octubre de 1789. AGI, Quito, legajo 380.

39 Despacho del virrey de Santa Fe, Santa Fe, 25 de noviembre de 1789. AGI, Quito, legajo 380 . 
la elección de alcaldes ordinarios dieron pie a nuevas quejas. Fue otra vez Joaquín Pareja quien acusó a Pizarro de intervenir en ese proceso pidiendo descaradamente los votos para sus protegidos o el cobro de hasta 500 ó 1.000 pesos a quienes pretendían los empleos. Aún más, sostuvo que aquél cercaba la casa capitular con soldados para presionar e intimidar en los días señalados para las elecciones. Asimismo consideró un menoscabo de la jurisdicción del Cabildo el que se le prohibiera celebrar sesión alguna sin la presencia del gobernador o su teniente y que con motivo de tales ocasiones los regidores hubieran de acompañar a su casa a la autoridad ${ }^{40}$.

No era ninguna novedad que el gobernador Pizarro deseaba consolidar su control sobre la institución. En realidad era una política acorde con las directrices centralistas de José de Gálvez. Fue precisamente su hermano José García de León y Pizarro, como visitador general y presidente de Quito, el que dio los primeros pasos en tal sentido. Aprovechando la supresión de los corregimientos y que las atribuciones de los corregidores pasaron a la autoridad superior, implementó una serie de medidas dirigidas a la adecuación del funcionamiento de los Cabildos a la nueva normativa. Con tal fin elaboró en 1782 una Instrucción que en sus 10 capítulos venía a limitar la autonomía municipal en beneficio del superior gobierno ${ }^{41}$. Su aplicación en Quito levantó las protestas del Cabildo de la ciudad pero sus regidores no lograron imponer sus argumentos $^{42}$. Otro tanto quiso hacer el de Guayaquil con la movilización del alférez Pareja y un grupo de regidores pero tal iniciativa estaba condenada al fracaso. La Instrucción había sido aprobada por la Corona y la propia Real Audiencia respaldaba el proceder del gobernador al encomendarle que era «muy conveniente al servicio del Rey y tranquilidad pública asista a los cabildos que se hubiesen de celebrar en aquella ciudad y que cuando no, lo execute su teniente auditor de guerra previniendo al Ayuntamiento no proceda a celebrar ninguno sin asistencia de uno o de otro» ${ }^{43}$.

En medio de este ambiente hostil resulta extraño que el Cabildo se mostrara en 1783 sumamente elogioso hacia el gobernador. Lo retrataba en esta ocasión como un "genio audaz y laborioso» que había «desempeñado todos los deberes con una satisfacción increíble», enumerándolos con gran detalle y jú-

40 Representación de Joaquín Pareja al Rey, Guayaquil, 4 de diciembre de 1787, AGI, Quito, legajo 271.

41 Instrucción para el mejor gobierno y dirección del Cabildo», Quito 21 de agosto de 1782, AGI, Quito, legajo 370.

42 Sobre esta cuestión véase Molina Martínez, 2009: 531-545.

43 Real Provisión de la Audiencia de Quito, Quito, 7 de febrero de 1782, AGI, Quito, legajo 380 . 
bilo ${ }^{44}$. Como ya ocurriera en 1780 , los esfuerzos realizados para la defensa y fortificación de Guayaquil merecieron la más alta valoración:

«Solamente ahora se sabe que Guayaquil está en disposición de una vigorosa defensa. Desde que gobierna este Señor hemos visto por nuestros propios ojos los admirables efectos del fuego de que no se tenía sino una noticia confusa... La eficacia del Señor Don Ramón García de León y Pizarro es quien ha sacado a esta ciudad del ser, como suele decirse, de la nada. Su vigilancia indeclinable ha logrado colocarla en el rango de las plazas más fuertes... Atento al bien público, pospone sus comodidades a lo que puede hacer feliz y lucido este vecindario de su cargo» ${ }^{45}$.

Se congratulaban los regidores de que tanto adelanto se hubiera llevado a cabo con gran economía de gasto. De los casi 57.000 pesos gastados en las obras de fortificación y los 47.543 pesos a que ascendió la construcción de puentes, empedrado de calles, alameda y obelisco la Real Hacienda sólo aportó poco más de 7.000 pesos. El resto «se debe a los legales arbitrios e económico desvelo de su genio superior..., multas y donaciones particulares». Ante tanto celo concluían que

«no será bastantemente alabado un hombre que después de haber formado una nueva ciudad suntuosa; después de haber sacado del lodo, digámoslo así, a Guayaquil; después de dejar a la posterioridad unos monumentos sólidos cuyo mudo lenguaje hablará para siempre en elogios de su autor; después de todo esto, lejos de presentar una planilla de gastos considerables, proporcionados a las obras, muestra, por el contrario, un estado general de ahorros particulares... Tanta es la ventaja de un Jefe cuya conducta es conforme a la intenciones de Su Majestad, respecto de los otros. Nunca más a propósito deberá decirse que un magistrado cabal es el placer y las delicias de un pueblo instruido y sensato» ${ }^{46}$.

En el ámbito de la administración de justicia tampoco escatimaban elogios y se felicitaban de que «por medio de su conducta en esta parte principal, se goza de una tranquilidad perfecta en Guayaquil y su jurisdicción». Asimismo, resaltaban su interés en la rehabilitación de viviendas para la gente más pobre. «El Señor Gobernador — decían - halló recursos extraordinarios en su gran caridad, socorriendo a un número increíble de poseedoras destituidas [señoras viudas, pobres o miserables] con cantidades sacadas de la renta de Su Señoría... y aún con jornales pagados de su sueldo».

Tales afirmaciones estaban rubricadas por los regidores José Carbo y Unzueta, Miguel Antonio de Anzoátegui, José Gorostiza, Baltasar de Avilés,

44 Certificación del Cabildo de Guayaquil, Guayaquil, 5 de agosto de 1783, AGS, SGU, legajo 6828.

45 Idem.

46 Idem. 
Juan de las Veneras y Cevallos, Manuel Ignacio Moreno y Santisteban, doctor Antonio Marcos, Jacinto Sumalave, doctor Domingo Espantoso y Castro el escribano Alejo Guiraldes Pereyra y Castro. Teniendo en cuenta los frecuentes desencuentros entre capitulares y gobernador y a la vista de algunos de los firmantes de ese documento, sorprende que aquellas manifestaciones fuesen iniciativa del Cabildo; más bien parecen forzadas por el propio Pizarro en un ejemplo más de su presión y control sobre la institución. No termina de explicarse bien el cambio de opinión tan brusco realizado por parte de algunos capitulares. Por ejemplo, Baltasar de Avilés y el escribano habían puesto en evidencia el despropósito de José Mexía en el episodio de los músicos; el doctor Antonio Marcos, como se sabe, fue el autor de una dura representación contra Pizarro; otros, en cambio, fueron luego recusados para testificar en la residencia al ser considerados enemigos del gobernador.

Sin embargo, una vez más, la declaración oficial escondía comportamientos del gobierno poco éticas. Así, lo que en aquella certificación se catalogaba como una obra de gran utilidad para la ciudad, esto es, la construcción en la plaza de unos galpones en los que se levantaron hasta 52 covachas para la venta de alimentos, legumbres, etc., fue denunciado como una actuación lucrativa más del gobernador y perjudicial para los vecinos. La representación de Joaquín Pareja arrojaba datos preocupantes en este sentido. Entre ellos, que las covachas eran alquiladas por cuatro pesos, de los que uno recaudaba el Cabildo y los tres restantes se los quedaba Pizarro. Según Pareja, con estos ingresos acabó fundado un mayorazgo de cerca de 2.000 pesos anuales en detrimento de los propios de la ciudad. Similares perjuicios venía ocasionando al Cabildo el recién creado estanco de la cal cuyos beneficios se apropiaba asimismo el gobernador.

Las críticas de corrupción se extendían también a la usurpación que Pizarro y su grupo hicieran a la ciudad del comercio del cacao en beneficio propio. El autor de la representación anónima afirmaba que el principal sustento económico de Guayaquil estaba monopolizado por el gobernador y su teniente Pedro Mexía, con la complicidad del comandante de milicias, Manuel de Guevara, el administrador de alcabalas, Miguel García, el administrador de la renta del tabaco, Francisco Garaicoa y su contador, Nicolás Cornejo. Este clan presionaba a los productores de cacao para que les vendiesen el producto a precios inferiores a los del mercado, con el inevitable perjuicio para éstos. Por su parte, Antonio Marcos denunciaba que con semejantes prácticas Pizarro y Mexía habían obtenido sumas cercanas a los 20.000 y 14.000 pesos respectivamente. La queja estaba fundada en el hecho de que los beneficios del cacao debían recaer en la propia ciudad de Guayaquil, en virtud de la gracia que obtuvo del rey para exportar a Acapulco 10.000 fanegas anuales para paliar las pérdidas oca- 
sionadas por el incendio de 1764, y no en determinados particulares como ocurría en la práctica ${ }^{47}$.

Sobre estas conductas irregulares, ilustra bastante lo sucedido a raíz de la iniciativa tomada por Damián de Arteta. Este propuso al Cabildo que se le cediese por cuatro años la real gracia que tenía la ciudad de llevar a Acapulco las mencionadas 10.000 fanegas de cacao a cambio de contribuir con 100.000 pesos, que se destinarían a la construcción de un colegio de niñas y con otra elevada suma para levantar una casa de niños huérfanos. El Cabildo consideró positiva la iniciativa y para darle mayor respaldo propuso que el vecindario la apoyara con su firma. Lo cual no agradó al gobernador quien ordenó la paralización de la recogida de firmas y forzó la situación para que Joaquín Pareja no hiciese la defensa del proyecto de Arteta. Sin embargo, lejos de amedrentarse, el alférez real elevó al presidente de la Real Audiencia un escrito en el que exponía todos los pormenores del caso y acusaba al gobernador, por un lado, de la «opresión que padece el pueblo por privarlo de la gracia de remisión de cacaos» y, por otro, del «desaire de haber desaforado a la ciudad (a quien se concedió la gracia) de su distribución $»^{48}$.

Joaquín Pareja exhibió toda clase de documentos para corroborar sus afirmaciones. Uno de ellos, la correspondencia mantenida por Manuel de Guevara con productores de cacao, se ofrece como un buen testimonio de las prácticas monopolistas del grupo de Pizarro, al demostrar que los productores de cacao se veían forzados a la venta de la mercancía a un precio inferior al del mercado. Una carta escrita por la misma esposa del gobernador, Mariana Zaldúa, al propio Joaquín Pareja revela suficientes pistas sobre aquellas prácticas. En ella podía leerse lo siguiente:

«Con el dador de ésta, D. Antonio Cornejo, remito a vuesamerced trescientos pesos para que me haga el favor de comprarme para el año que viene 100 cargas de cacao y si pudiese comprar más barato mejor, pero en caso de que ni aún a los tres pesos carga se pudiese comprar, puede vuesamerced pagarlo aunque sea dos reales más... que yo satisfaré a vuesamerced lo que faltase, pero espero de la eficacia y diligencia de vuesamerced que no será menester... pues no dudo me servirá en esto

47 Los incendios eran una amenaza constante en Guayaquil y por ello merecieron la atención de los gobernantes. De la época que nos ocupa data una Instrucción formada por el visitador José García de León y Pizarro en 1778, luego completada por José Mexía con nuevos artículos. Su contenido puede consultarse en Loor Jara, 2006: 217-229. Un acercamiento general a los efectos del fuego en Guayaquil lo ofrece Laviana Cuetos, 2007-2008: 81-101.

48 Así consta en la Representación que Pareja envió al Rey el 4 de diciembre de 1787. El presidente de la Real Audiencia le respondió lacónicamente el 19 de octubre de 1787 informándole que se había «juntado su representación al expediente que allí pendía sobre el asunto». 
como si fuera negocio propio y le suplico sea con todo sigilo porque me importa así» ${ }^{49}$.

Más allá de la excelente imagen que algunos de sus allegados transmitieron del gobernador de Guayaquil y del éxito que para la Real Hacienda alcanzó su gestión, lo cierto es que levantó las protestas y las denuncias de un sector de la población, que creyó que la justicia del rey no era aplicada y que las leyes eran violentadas en su ejecución. Las tres representaciones críticas con la forma de gobierno de Pizarro que llegaron a manos del rey en 1787 eran la expresión del descontento de un sector de vecinos. Uno de ellos, Antonio Marcos, resumía la situación con este desolador panorama:

«De todos los ramos hacen pillaje. La justicia se vende al mejor postor. Las rentas reales son unas prensas en las que se exprime al vasallo hasta extraer la última gota de sangre para mantener el lujo de una multitud de empleados... Su método de gobierno es absolutamente despótico. El gobernador lo ejerce al descubierto. Mexía con inaudita simulación, pues abusa de sus luces para honestar sus iniquidades... Ejecuta el mal por segundas manos y resortes ocultos para ser juez de sus propias venganzas... Todos los que no le rinden adoración son sus enemigos capitales a quienes persigue de muerte. Tiene formadas a prevención sumarias de los más atroces cargos para taparles la boca si hacen semblante de quejarse, o destruirlos. Así van perdidos ya muchos vecinos honrados. Una general opresión es el resultado de sus políticas máximas. Dispone a su antojo de la fe de los escribanos y de los testigos. Solamente aparece en juicio lo que quiere. Su voluntad es la suprema ley. Los recursos de queja se hallan interceptados. Es preciso padecer o morir. Las haciendas y las vidas de los súbditos son el juguete de las pasiones de los dos. Los adúlteros, depresores, usureros y demás son los únicos que logran su confianza y los ministros fieles a sus designios. Todo el rigor se guarda para los casados, las viudas y los huérfanos» ${ }^{50}$.

Por su parte, la representación anónima apostillaba:

«El mayor perjuicio que sufre la ciudad para su destrucción es la falta de verdadera justicia administrada conforme al espíritu de las leyes. Aquí se hace un comercio público de los caudales de los vecinos, sujetándolos a interminables pleitos, porque de aquí les proviene una crecida ganancia al gobernador y su teniente... Las rentas que V.M. les da de su Real Erario no exceden de lo necesario para una sobresaliente decencia; pues ellos se hacen de tantos miles de dinero y alhajas que el mercader más grueso no alcanza a sus pisadas ni de lejos» ${ }^{51}$.

49 Carta de Mariana Zaldúa a Joaquín Pareja, Guayaquil, 18 de julio de 1781, AGI, Quito, legajo 380 .

50 Representación de Antonio Marcos al rey, Guayaquil, 19 de diciembre de 1787, AGI, Quito, legajo 271.

51 Representación anónima sobre los negocios del gobernador de Guayaquil, Guayaquil, 4 de diciembre de 1787. AGI, Quito, legajo 271. 
La Corona intervino para esclarecer el alcance de semejantes testimonios. La misión fue encomendada inicialmente al oidor de la Real Audiencia de Quito, Fernando Cuadrado, pero fue cerrada en falso en medio de una gran polémica con el presidente Juan José de Villalengua y entre los mismos oidores $^{52}$. Del mismo modo, resultó frustrada la residencia encomendada a principios de 1790 a Juan Moreno Avendaño, al quedar manifiesta una notoria inclinación de éste por el partido de los García de León y Pizarro ${ }^{53}$. Finalmente, la designación recayó sobre Anacleto de Casas y Alcalde según providencia de Estanislao Joaquín de Andino, regente de la Audiencia quiteña, quien a su vez había sido requerido para ello por el virrey José de Ezpeleta ${ }^{54}$. Andino vio en Casas «un sujeto de imparcialidad y rectitud y libre de nota» y, convencido de que se trataba de la persona más indicada, firmó su nombramiento el 21 de junio de $1791^{55}$. El Cabildo de Guayaquil le reconoció como juez de residencia pocos días después y sin mayor dilación dio inicio a las pesquisas, actuando como escribano Pedro Monteserín y Estrada, procedente de Cuenca, toda vez que los tres escribanos de Guayaquil habían servido durante el gobierno de Pizarro y eran también objeto de la residencia.

Dirigió el juez sus primeras medidas a establecer la autoría de las representaciones enviadas a la Corte contra García de León y Pizarro. Para ello hizo comparecer al alférez real, Joaquín Pareja, firmante de una de ellas, quien bajo juramento confirmó ser responsable del texto y justificó su proceder «como buen patriótico y en defensa de los de los reales intereses, que veía defraudados». Aún más, dijo estar dispuesto a demostrar que era cierto todo cuanto en ella se afirmaba y a documentar cuanto fuera necesario «para hacer ver se movió con verdad para hacer dicha denuncia» ${ }^{56}$. Considerando el juez que el contenido de su representación tenía bastantes puntos comunes con la de Antonio Marcos y la anónima, decidió no citar a estos últimos, máxime cuando el primero estaba

52 Molina Martínez, 2008: 153-173.

53 El entonces presidente de la Audiencia, Mon y Velarde, confesaba al virrey lo inoportuno de aquella designación por recaer en una persona «no bien libre de imparcialidad por su particular adherencia al denunciado y decidida estimación de toda su familia» (Carta de Antonio Mon y Velarde a José de Ezpeleta, Quito, 18 de julio de 1790, AGI, Quito, legajo 270).

${ }^{54} \mathrm{La}$ Real Orden de 23 de noviembre de 1790 instaba al virrey Ezpeleta a que tomase las medidas oportunas para indagar sobre los cargos formulados contra el gobernador Ramón García de León y Pizarro; aquél trasladó el encargo, mediante Orden de 31 de marzo de 1791, a Estanislao Joaquín de Andino.

55 Orden del regente de la Real Audiencia al juez de residencia Anacleto de Casas y Alcalde, Quito, 30 de junio de 1791, AGI, Quito, legajo 380.

56 Certificación de Pedro Monteserín y Estrada, Guayaquil, 19 de agosto de 1791. AGI, Quito, legajo 380. 
avecindado en la ciudad de Cuenca y del segundo, por razones obvias, carecía de pistas para su identificación. Para Casas y Alcalde no había ninguna duda de que estas dos últimas representaciones ofrecían muchos puntos afines y podían situarse sin dificultad en el ámbito de influencia del alférez Pareja.

El interés de éste en corroborar sus denuncias llegó al extremo de proporcionar al juez una relación de vecinos que estarían dispuestos declarar en el mismo sentido. De los sujetos propuestos, unos lo fueron para que dejaran constancia de las cantidades de dinero que habían pagado al gobernador, ya fuera para que se les eximiese de la milicia, ya fuera para que se le diese algún empleo en ella. Otros para que enumeraran los perjuicios de que habían sido objeto con motivo y pretexto de la construcción del galpón de San Carlos, si se pagó a los trabajadores empleados y qué trato se dispensó a los presos, soldados e indios ocupados en las obras. Otros para que expresaran las cantidades de madera que estuvieron obligados a contribuir sin remuneración alguna. Otros para que confirmaran las multas de que fueron víctimas y sus razones. A Juan Ignacio de Vera y a José Ignacio de Aguilar se les citó para que hablaran del dinero que habían desembolsado para que se les nombrara jueces pedáneos. En el mismo sentido, se requería a Pablo Mendiota para que detallara la cantidad de dinero que había abonado para obtener una vara de teniente de alcalde de Hermandad y a José Bustamante para que confirmara si pagó entre 400 y 500 pesos por el empleo de teniente del pueblo de Palenque. A otros se les instaba a que dijeran si realizaron compras de cacao por la mitad del precio de su verdadero valor. Al regidor Andrés Campuzano se le pedía que declarara qué tipo de contrata firmó con el gobernador y con qué finalidad. Damián de Arteta, por su parte, debía detallar las sumas de dinero, plata labrada y otros efectos que entregó a Pizarro como resultado de la venta del cacao remitido a México; también si era cierto que Bruno Polanco envió al gobernador 7.000 pesos de ropas para que fueran entregados al comandante Bernardo Roca. Por si ello no fuera suficiente, el ofrecimiento de Joaquín Pareja comprometía también al mismo Cabildo al que instaba a que declarase sobre la compra de votos para acceder a las plazas de alcaldes ordinarios y otros oficios concejiles y sobre el precio con que se alquilaban las covachas instaladas en la plaza y lo que se cobraba realmente por ellas ${ }^{57}$.

Evidentemente todas las personas incluidas en aquella relación formaban parte de su entorno más cercano Personajes como Francisco y Andrés Campuzano, Juan Millán y Pinto, Martín de Icaza, Miguel García, José Crespo

57 Petición de Joaquín Pareja a Anacleto de Casas y Alcalde, Guayaquil, 19 de agosto de 1791. AGI, Quito, legajo 380. 
Avilés, Severino Franco, Antonio Juárez, Antonio Parames, Ignacio Ruiz, José Merino, Nicolás Campe, Juan Casilari, José Paredes, Andrés Anzoátegui, Cristóbal Holguín o Antonio Campián no dudarían en ratificar punto por punto las críticas de Pareja. El propio juez de residencia era consciente de esta circunstancia y por ello rechazó algunas de las comparecencias solicitadas. Por otro lado, la intervención de Agustín de Oramás al censurar y declarar nulos los testigos propuestos por Pareja terminó por frustrar la estrategia del alférez real. Oramás, vecino de Guayaquil, capitán de infantería del regimiento de milicias y administrador de Temporalidades, era una persona estrechamente vinculada al gobernador y al que éste le había confiado su defensa en el juicio de residencia. Según Oramás aquellas personas no podían testificar porque «son tenidos como odiosos y sospechosos» y ser notoria «la enemistad y ofensa que tienen hacia Pizarro» ${ }^{58}$. Los argumentos de su exclusión eran de diversa índole; unos aludían al hecho de tratarse de personas encausadas por el gobernador durante su mandato lo que hacía presumir que su testimonio sería interesado; otros, por su parte, se centraban en la existencia de relaciones de parentesco o compadrazgo con Pareja, lo que, del mismo modo, era considerado como factor que restaba imparcialidad a las declaraciones. El cuadro I detalla las personas que, según Oramás, se encontraban en esta situación y, por tanto, descalificadas para ser tenidas en cuenta en el proceso.

Cuadro I. Relación de opositores al gobierno de Pizarro

\begin{tabular}{|l|l|}
\hline Joaquín Pareja & $\begin{array}{l}\text { Cabeza de la oposición a Pizarro y principal } \\
\text { capitulante }\end{array}$ \\
\hline Sus hijos, criados, ahijados, comadres & Hermano de Pareja \\
\hline Dr. Ignacio Pareja & $\begin{array}{l}\text { Hermana de Pareja y viuda de Antonio Ma- } \\
\text { xim, un capitulante }\end{array}$ \\
\hline Josefa Pareja & Yerno de Pareja \\
\hline Manuel Avilés y sus tres hermanos y criados & Yerno de Pareja \\
\hline Bernardo Echeves & Yerno de Echeves. \\
\hline Alonso Aceval & Capitulante y sobrino de Pareja \\
\hline José Morán y todos sus hermanos y criados & Cuñado de Pareja \\
\hline Jacinto Coello y sirvientes &
\end{tabular}

58 Petición de Agustín de Oramás Romero a Anacleto de Casas y Alcalde, Quito, 16 de agosto de 1791. AGI, Quito, legajo 380. 
Cuadro I. Relación de opositores al gobierno de Pizarro (Continuación)

\begin{tabular}{|c|c|}
\hline Gaspar Gutiérrez y sirvientes & Cuñado de Pareja \\
\hline José del Campo & Capitulante e íntimo de Pareja \\
\hline José Gorostiza, alguacil mayor & Capitulante e íntimo de Pareja \\
\hline Alejo Guiraldes, escribano de cabildo & Capitulante \\
\hline Manuel Ignacio Moreno, regidor & Capitulante e íntimo de Pareja \\
\hline Francisco Catoyna, regidor & Capitulante e íntimo de Pareja \\
\hline Manuel Ruiz, comerciante & Amigo de Pareja \\
\hline Manuel Argandeña & Concuñado de Manuel Ruiz \\
\hline Pedro Santander & Cuñado de los dos anteriores \\
\hline Dr. Domingo Espantoso & Consultor y abogado de Pareja \\
\hline Santiago Espantoso & Padre del anterior \\
\hline Antonio Alonso Parames & Cuñado de Espantoso y amigo de Pareja \\
\hline Damián de Arteta & $\begin{array}{l}\text { Íntimo de Pareja, inculpado en asuntos de } \\
\text { cacao }\end{array}$ \\
\hline Miguel Anzoátegui & Amigo de Pareja y acreedor suyo \\
\hline Ignacio Cortázar, vicario de Guayaquil & $\begin{array}{l}\text { Amigo de Pareja y enemigo declarado de } \\
\text { Pizarro }\end{array}$ \\
\hline Juan Bautista Elizalde, mercader & Casado con una sobrina de Ignacio Cortázar \\
\hline $\begin{array}{l}\text { Miguel García de Cáceres, administrador de } \\
\text { Aduana }\end{array}$ & Íntimo de Pareja, con expedientes abiertos \\
\hline Gabriel de Labayen & Suegro del anterior e íntimo de Pareja \\
\hline Pablo Labayen & Hijo del anterior y cuñado de Miguel García \\
\hline Martín de Icaza & Íntimo de Pareja \\
\hline Dr. Isidro Figuerola & Íntimo de Pareja y de Ignacio Cortázar \\
\hline José Crespo y sus hijos & Íntimo de Miguel García \\
\hline Juan Millán y Pinto & Oráculo de Miguel García \\
\hline Dr. Alonso Cepeda & Íntimo de Ignacio Cortázar \\
\hline José Paredes & Amigo de Pareja \\
\hline Pablo Engracia & Enemigo declarado del gobernador \\
\hline Nicolás Cornejo y Flor & Íntimo de Pareja \\
\hline
\end{tabular}


Cuadro I. Relación de opositores al gobierno de Pizarro (Continuación)

\begin{tabular}{|c|c|}
\hline Antonio Cornejo & $\begin{array}{l}\text { Hermano del anterior y deudo de Damián } \\
\text { Arteta }\end{array}$ \\
\hline Antonio Campián & Apremiado a salir de la ciudad por extranjero \\
\hline Familia de los Plazartes & Reprehendidos por el gobernador \\
\hline Rvdo. Padre Maestro Ávila & Reprehendido por el gobernador \\
\hline Rupercio Robles & Íntimo de Pareja \\
\hline Joaquín Coello & $\begin{array}{l}\text { Marido de la Penedo, encausado por el } \\
\text { gobernador }\end{array}$ \\
\hline Félix Rubio de Benito & Adverso al gobernador \\
\hline Toda la familia Vera & Adversa al gobernador y encausada \\
\hline Francisco Campuzano & Íntimo de Pareja \\
\hline Andrés Campuzano & Hijo del anterior y regidor, íntimo de Pareja \\
\hline Francisco Campuzano & Hermano del anterior \\
\hline Nicolás Campe & Encausado \\
\hline Santiago Vítores & Yerno del anterior \\
\hline Severino Franco & Íntimo de Pareja \\
\hline Manuel Córdoba y su hijo & Íntimos de Pareja \\
\hline Dr. Jacinto Bodero & Encausado por el gobernador \\
\hline Ignacio Ruiz Romera, teniente de la Cía. Fija & Íntimo de Pareja \\
\hline Antonio Juárez, alférez de la misma Cía. & Íntimo de Pareja \\
\hline Juan Indabur, capitán de la misma Cía. & Íntimo de Pareja \\
\hline José Merino & Parcial de Pareja \\
\hline Dr. Pedro Alcántara Bruno & Parcial de Pareja \\
\hline Dr. Ignacio Casaus & Parcial de Pareja \\
\hline Dr. Fermín Llorente & Parcial de Pareja \\
\hline Guillermo Salcedo & Parcial de Pareja \\
\hline José Gago & Parcial de Pareja \\
\hline Agustín López & Parcial de Pareja \\
\hline Juan de la Torre & Parcial de Pareja \\
\hline Manuel Iturralde & Parcial de Pareja \\
\hline
\end{tabular}


Anacleto de Casas y Alcalde admitió la recusación presentada por Agustín de Oramás, pero al mismo tiempo, y por similares motivos, también excluyó a los individuos propuestos por éste para la defensa del gobernador ${ }^{59}$. Esta circunstancia complicó el desarrollo de la residencia y dejó patente la frustración y el malestar del juez, quien llegaría a reconocer que, «cualquier examen de los testigos era un medio poco seguro para el descubrimiento de la verdad y que la averiguación era si no imposible, por lo menos muy dificultosa ${ }^{60}$. Sin embargo, no eran éstas las únicas presiones y anomalías que pudo observar en el desempeño de su labor.

No pocas dificultades encontró por parte de los escribanos de cabildo y de gobierno, reacios a colaborar en la residencia, descubriendo que hacían causa común con Pizarro y Mexía. Le llamó particularmente la atención al juez el cambio de actitud del escribano de cabildo, Alejo Guiraldes Pereira, que antes había avalado con su firma la crítica representación de Pareja y ahora defendía a José Mexía hasta el «extremo de prostituir la religión del juramento y la legalidad de su oficio para favorecerle $\rangle^{61}$. En cambio, nada le sorprendieron las trabas y evasivas en la entrega de documentación por parte del escribano de gobierno, José Vázquez Meléndez, ya que sobre él recaían varias acusaciones de fraude en la recaudación de las penas de cámara. Pero la mayor oposición la encontró Casas en José Mexía. La sorda labor llevada a cabo por éste, presionando a los vecinos de Guayaquil con el beneplácito de un sector importante de la Audiencia de Quito, entonces presidida por Juan José de Villalengua, familiar de Ramón Pizarro, logró sus objetivos y terminó minando la fortaleza del juez. Con desánimo admitió éste que hasta aquellos individuos que él consideraba imparciales y competentes para declarar le habían suplicado que «no se valiera de ellos para testigos porque no querían sonar en la residencia, intimidados de la protección que suponían tenía el teniente Mexía de algunos ministros de esta Real Audiencia» ${ }^{62}$.

Ya fuera por la intimidación referida, ya fuera por el alivio de encontrarse el gobernador por entonces lejos de Guayaquil, lo cierto es que las demandas presentadas contra Pizarro fueron muy pocas y, como observó Casas, en Guayaquil estaba muy extendida la opinión de que a sus vecinos ya no les importaba nada el juicio de residencia y que decían sentirse satisfechos tras la partida

59 Auto de Anacleto de Casas y Alcalde, Guayaquil, 25 de agosto de 1791. AGI, Quito, legajo 380 .

60 Informe de Anacleto de Casas y Alcalde al Rey, Quito, 15 de abril de 1792. AGI, Quito, legajo 380 .
61 Idem.
62 Idem. 
del gobernador Pizarro a Salta y de su teniente Mexía a Quito63. Un dato revelador de esta nueva situación lo brinda el propio Joaquín Pareja, antes tan crítico con Pizarro y Mexía. Refiere Casas que en más de una ocasión aquél le había trasladado su opinión de que lo mejor hubiera sido abstenerse de hacer reclamación alguna en el juicio de residencia; pero el hecho de ser citado a declarar y el impulso de demostrar la veracidad de las denuncias, que había interpuesto en su día contra el gobernador y su círculo, le obligaron a personarse en la causa como el vecino más beligerante ${ }^{64}$.

Anacleto de Casas cerró el juicio de residencia convencido de no haber llegado hasta el fondo de la cuestión y, todavía más grave, con el sentimiento de haber sido desautorizado por autoridades no competentes en el caso. Así ocurrió con las penas impuestas a Pedro Mexía y al escribano Vázquez Meléndez; al primero, una multa de más de 6.000 pesos; al segundo, tras declararlo «escribano falsario, infame e inhábil», lo acusó del delito de falsedad en la documentación con la obligación de personarse como reo ante el Consejo de Indias para que éste, a la vista de los autos, dictase la pena que correspondiera $^{65}$. Ambas sentencias fueron recurridas por los interesados en la Audiencia de Quito. Como resultado de estas providencias, Meléndez fue indultado de acudir a España y que el Consejo se pronunciara sobre los autos; Mexía, por su parte, logró que no se ejecutase la multa a la que se le condenó. Ante esta circunstancia Casas no ocultó su pesar al monarca poniendo de manifiesto el agravio de que había sido objeto y la burla a la justicia perpetrada en los mismos tribunales. Después de considerar aquellos recursos contra «mis justos y moderados procedimientos en el juicio de residencia» como indebidos, calificó las providencias de la Audiencia como una «ofensa a la autoridad y jurisdicción de Vuestro Supremo Consejo de las Indias... con desaire y sonrojo de mi persona $»^{66}$. No le faltaba razón, ya que era a él y no a la Audiencia a quien competía conocer y juzgar en el juicio de residencia. Sin embargo, como demostró Tamar Herzog, el alto organismo de justicia gozaba de una amplia consideración social, toda vez que se le identificó con el monarca. Respeto que, pese a las acusaciones de nepotismo, corrupción o intereses de partido de sus oidores nunca llegó a ser menoscabado. Su conclusión de que la práctica judicial fue mediatizada por protagonistas influyentes o por elites locales concretas, reduciendo al mínimo la separación entre los intereses reales y los de los particulares, puede aplicarse también en este
63 Idem.
64 Idem.
65 Idem.
66 Idem. 
caso, aunque tuviera lugar unas décadas más tarde del marco cronológico fijado en su monografía ${ }^{67}$. El papel desempeñado por la Audiencia parece demostrar que las relaciones de amistad, compadrazgo o simple compromiso tuvieron prioridad sobre las decisiones estrictamente judiciales en beneficio de intereses particulares.

En cuanto a Ramón García de León y Pizarro, como se ha dicho, apenas fueron presentados cargos contra él. Únicamente trece testigos, «pobres menestrales», como reconocía Casas al rey, acudieron a la causa. La mayoría lo hizo para demandar ciertas cantidades a cuenta de la madera adelantada para las obras de fortificación y los jornales ejecutados en aquella obra. En ninguna de ellas encontró Anacleto de Casas suficiente consistencia y desistió de darles curso $^{68}$. Los únicos dos cargos que prosperaron contra el gobernador fueron la indolencia con que procedió en la recaudación, cuenta y reintegro del ramo de penas de cámara y la desidia con que practicó la visita a la cárcel, no más de dos veces al año. A la vista de ello el Consejo de Indias absolvió a Pizarro y atenuó las penas impuestas a su teniente gobernador, Mexía, y a su escribano, Vázquez Meléndez ${ }^{69}$.

Lo expuesto hasta aquí ilustra bien sobre determinados comportamientos de la burocracia colonial, sus actitudes y formas de afrontar el ejercicio del poder. Comportamientos que, aun estando dentro de la estricta legalidad, podrían ser cuestionados por su dudosa ética y moralidad. Las amenazas, sobornos, medidas de presión, favoritismos, etc. no fueron ajenos a la práctica política ejercida por Ramón Pizarro y parecen tan obvios como viejos en el tiempo. Puede resultar curioso que una sentencia absolutoria viniera a poner fin a tantos expedientes que comprometían la rectitud de su gobierno y similar valoración cabría hacer también de la actuación de su hermano José y otros ministros. Parece que a la Corona sólo le interesó que sus gobernantes obtuvieran los resultados que se esperaban del programa político encomendado, sin reparar demasiado en conductas personales, estrategias o planteamientos morales. El desempeño ético del cargo no importaría tanto como la presentación de un balance positivo de las arcas reales o el logro de los objetivos diseñados por el reformismo. Es evidente que muchas de las críticas formuladas contra Ramón

67 Herzog, 2004. Interesa especialmente la lectura de los capítulos 3 (Officers and society) y 4 (Society and the Adminsitration of Justice): 127-179.

68 Informe de Anacleto de Casas y Alcalde al Rey, Quito, 15 de abril de 1792, AGI, Quito, legajo, 380.

69 Castillo, 1978: 252. La sentencia final absolutoria fue dada por el Consejo de Indias el 6 de octubre de 1794. El expediente completo sobre el juicio de residencia se halla en el Archivo Histórico Nacional de Madrid, sección Consejo de Indias, legajos, 20.621 y 20.622. 
Pizarro sobre su gestión en Guayaquil provenían de sus adversarios o de individuos simplemente perjudicados por las nuevas directrices políticas puestas en marcha; pero también lo es que, tras esas quejas, abundan las evidencias de prácticas irregulares, impropias y hasta corruptas que aquel gobernante puso en práctica buscando el beneficio propio y, desde luego, amparado en una tradición bien consolidada.

En definitiva, lo planteado en nuestro texto viene a sustentar la tesis de cómo el desempeño de un cargo dentro de la burocracia colonial fue utilizado como un «patrimonio» personal que facultaba para disponer con libertad de ciertas preeminencias, obtener beneficios ilícitos o ganar voluntades. De alguna manera, la función pública devino en una forma de inversión privada por medio de la cual el titular, además de lograr ganancias económicas, podía aumentar sus privilegios, extender su red influencias y, por lo tanto, su poder.

\section{BIBLIOGRAFÍA}

Andrien Kenneth, «Corruption, Inefficiency and Imperial decline in the Seventeenth-Century of Peru», The Americas, 41/1 (1984): 1-20.

Andrien Kenneth, «El Corregidor de indios, la corrupción y el estado virreinal en Perú (1580-1630)», Revista de Historia Económica, 3 (Madrid, 1986): 493-521.

Andrien, Kenneth, «Corruption, Self Interest, and the Political Culture of Eighteenth-Century Quito», Virtue, Corruption and Self Interest. Political Values in the Eighteenth Century, ed. R. K. Matthews, Bethlehem, 1994.

Arribas, Filemón, «Nuevas noticias sobre D. Ramón García de León y Pizarro», Revista de Indias, XXX/119-122 (Madrid, 1970): 21-48.

Cañeque, Alejandro, «Cultura viceregia y estado colonial. Una aproximación crítica al estudio de la Historia Política de la Nueva España», Historia Mexicana, LI/1 (México, julio-septiembre, 2001): 5-57.

Castillo, Abel Romeo, Los gobernadores de Guayaquil del siglo XVIII (Notas para la historia de la ciudad durante los años de 1763 a 1803), Archivo Histórico del Guayas, Guayaquil, 1978.

Herzog, Tamar, Upholding Justice: Society, State and the Pena System in Quito (1650-1750), Ann Arbor, University of Michigan Press, 2004.

Laviana Cuetos, M. ${ }^{a}$ Luisa, «El habitat urbano y la lucha contra el fuego en el Guayaquil colonial», Revista del Archivo Histórico de Guayas (Guayaquil, segunda época: 3-4, II semestre 2007-I semestre 2008): 81-101. 
Loor Jara, Susana (trascp.), «Expediente sobre precaver incendios en la ciudad de Guayaquil, 1784», Revista del Archivo Histórico de Guayas, segunda época n. ${ }^{\circ} 1$ (Guayaquil, 2006): 217-229.

Molina Martínez, Miguel, «Conflictos en la Audiencia de Quito a finales del siglo XVIII», Anuario de Estudios Americanos, 65/1 (Sevilla, 2008): 153-173.

Molina Martínez, Miguel, «Autonomía frente a centralismo. La defensa de los fueros del Cabildo de Quito (1782-1798)», Manuela Cristina García Bernal y Sandra Olivero Guidobono (coords.), El municipio indiano: Relaciones interétnicas, económicas y sociales, Universidad de Sevilla, Secretariado de Publicaciones, 2009: 531-545.

Moreno Cebrián, Alfredo y Nuria Sala i Vila, El premio de ser Virrey. Los intereses públicos y privados del gobierno virreinal en el Perú de Felipe V, Madrid, Consejo Superior de Investigaciones Científicas, 2004.

O’Phelan, Scarlet, «Orden y control en el siglo XVIII. La política borbónica frente a la corrupción fiscal, comercial y administrativa», Felipe Portocarrero (ed.), El pacto infame. Estudios sobre la corrupción en el Perú, Lima, Red para el Desarrollo de las Ciencias Sociales en el Perú, 2005: 13-33.

Pietschman, Horst, «Burocracia y corrupción en Hispanoamérica colonial: una aproximación tentativa», Nova Americana, 5 (Turín, 1982): 11-37.

Pietschman, Horst, El Estado y su evolución al principio de la colonización española, Mexico, FCE, 1989.

Pietschmann, Horst, «Corrupción en las Indias españolas: Revisión de un debate en la historiografía sobre Hispanoamérica colonial», en Manuel González Jiménez, Horst Pietschmann, Francisco Comín y Joseph Pérez (coords.), Instituciones y corrupción en la Historia, Instituto Universitario de Historia Simancas, Universidad de Valladolid, 1998: 31-52.

Pietschmann, Horst, «Los principios rectores de la organización estatal en las Indias», en Antonio Annino y Francois Xavier Guerra (coords.), Inventando la Nación, Mexico, FCE, 2003: 47-84.

Ramos Gómez, Luis Javier, «La pugna por el poder local en Quito entre 1737 y 1745 según el proceso contra el presidente de la Audiencia José de Araujo», Revista Complutense de Historia de América, 18 (Madrid, 1992): 179-196.

Ramos Gómez, Luis Javier, «La acusación contra el presidente electo don Juan José de Araujo y Río por la introducción de mercancías ilícitas a su llegada a Quito en diciembre de 1736», Boletín de la Academia Nacional de Historia, LXXII, 153/154 (Quito, 1993): 249-272.

Ramos Gómez, Luis Javier, «Enfrentamientos entre grupos de poder por el dominio del Cabildo de Quito entre 1735 y 1739», Revista Complutense de Historia de América, 31 (Madrid, 2005): 53-77. 
Ruigómez Gómez, M. ${ }^{a}$ Carmen, «Alianzas y rivalidades en el cabildo de Quito: el remate de regidurías en 1736», Contrastes. Revista de Historia Moderna, 13 (2004-2007): 77-92.

Saguier, Eduardo, «La corrupción administrativa como mecanismo de acumulación y engendrador de una burguesía comercial local», Anuario de Estudios Americanos, XLVI (Sevilla, 1989): 269-303.

Torres Arancivia, Eduardo, Corte de virreyes. El entorno del poder en el Perú del siglo XVII, Lima, Pontificia Universidad Católica del Perú, 2006.

Torres Arancivia, Eduardo: «El problema historiográfico de la corrupción en el antiguo régimen. Una tentativa de solución», Summa Humanitatis. Revista electrónica Interdisciplinaria del Departamento de Humanidades, 1: 0 (Pontificia Universidad Católica del Perú, Lima 2007).

Fecha de recepción: 22 de marzo de 2010

Fecha de aceptación: 28 de septiembre de 2010

\section{Political efficiency, ethics and corruption in the Guayaquil government (1779-1790)}

The government of Ramón Garcia de León y Pizarro received praise from the Crown and, later on, from the ranks of historical research. However, some of his acts raise questions for their dubious ethics and morality. Threats, bribes, strong-arm tactics, favoritism, etc. were prevalent among his political practices and for his own benefit, as well as the benefit of his clan. This article analyses some of these irregular behaviors in the context of a debate on corruption in colonial bureaucracy.

KEY WORDS: Guayaquil; $18^{\text {th }}$ century; corruption; colonial administration. 